\title{
Biomarker enzyme activities and ultrastructure of liver of the grass carp Ctenopharyngodon idella (Valenciennes, 1844) exposed to the organophosphate pesticide chlorpyrifos
}

\author{
MANDEEP KAUR AND RAJINDER JINDAL \\ Aquatic Biology Laboratory, Department of Zoology, Panjab University, Chandigarh - 160 014, India \\ e-mail: Mandeep.kaur15@hotmail.com
}

\begin{abstract}
The present investigation analysed the toxic effects of the organophosphate pesticide chlorpyrifos (CPF) on activities of biomarker enzymes viz., alanine transaminase (ALT), aspartate transaminase (AST), alkaline phosphatase (ALP) and acid phosphatase (ACP) as well as ultrastructural alterations in hepatocytes of grass carp Ctenopharyngodon idella exposed to sublethal concentrations $\left(1.44\right.$ and $\left.2.41 \mu^{\mathrm{g} \mathrm{l}^{-1}}\right)$ for 15, 30 and 60 days. The enzymes showed marked fluctuations post-pesticide treatment. The altered enzymes activities indicated disturbance in the structure and integrity of cell organelles. Ultrastructural alterations such as formation of crescent shaped nucleus along with condensed chromatin, margination of heterochromatin, severe breakdown and fragmentation of endoplasmic reticulum, deformed mitochondria with loss of cristae were observed in the pesticide exposed fishes. The findings revealed exposure period and concentration dependent response in hepatocytes. Ultrastructural changes could be correlated to corresponding alterations in the activities of marker enzymes. At both the toxicant concentrations, altered activities of AST and ALT as markers of glycolysis and protein metabolism indicated disturbances to the cellular metabolism. The observed changes in the liver enzyme levels could be used as sensitive biomarkers for pesticides contamination in grass carp.
\end{abstract}

Keywords: Chlorpyrifos, Ctenopharyngodon idella, Liver, Marker enzymes, Transmission electron microscopy

\section{Introduction}

Pesticides are recognised worldwide as a veritable means of controlling pests, at the same time such chemicals are highly toxic to non-target species in the environment (Rao, 2006a). Presently, there is an increasing concern world over on the indiscriminate use of such chemicals that result in environmental pollution and toxicity risk to non-target organism (Velisek et al., 2007). Among the various organisms present in the aquatic ecosystem, fishes are the one that are relatively more sensitive to changes in their surrounding environment. The pesticide concentration in the aquatic organisms increased manifold due to biomagnification than the concentration present in the ecosystem (Martin and Knaeur, 1973). The pesticides liberated into aquatic ecosystem have a tremendous adverse effect on fish and thereby to man. Chlorpyrifos is a broad-spectrum organophosphate (OP) with wide application in the field of agriculture and has wide variation of toxicity among different species. It is the second largest selling OP agrochemical in India.

The liver is an important organ involved in metabolic processes and in detoxification of xenobiotics. Pesticides may accumulate in the liver and cause pathological changes (Braunbeck et al., 1990). There are many studies on liver ultrastructural alterations induced by pesticides in aquatic organisms (Khangarot, 1992). The type of liver injury is often dependent not only on the toxicant and its mechanism of action but also on the duration of exposure (Jacobson-Kram and Keller, 2006). Evaluation of enzyme activities in the tissues and organs of aquatic organisms in the diagnosis of the effects of pollutants is one of the emerging areas in toxicological monitoring and remediation programmes (Oluah et al., 2005). Fluctuations in aspartate aminotransferase (AST) and alanine aminotransferase (ALT) activities reflect liver damage (Bernet et al., 2001). Further, alkaline phosphatase (ALP) is composed of several isoenzymes that are present in all tissues of the body, especially in cell membranes. These enzymes catalyse the hydrolysis of monophosphate esters and have wide substrate specificity. Such responses allow the fish liver to be considered as a good indicator of fish health status (Bowser et al., 1990; Brusle and Gonzalez, 1995). Investigations on biochemical and histological changes in fish liver has become an important tool to monitor the environmental exposure of fish to contaminants (Fernandes et al., 2008; Carrola et al., 2009). Keeping this in view, the present work was undertaken to evaluate the stress parameters by analysing biomarker enzyme levels and ultrastructural alterations in the liver of the grass carp Ctenopharyngodon idella (Valenciennes, 1844) exposed to chlorpyrifos. 


\section{Materials and methods}

\section{Procurement of fish and acclimatisation}

Fingerlings of Ctenopharyngodon idella (10 $2 \mathrm{~g}$, $10 \pm 2 \mathrm{~cm}$ ), were collected from Nanoke Fish Seed Farm, Nanoke, District Patiala, Punjab and were safely brought in aerated water packed polythene bags. They were acclimatised to the laboratory conditions for 15 days in glass aquarium and fed with pelletised supplementary feed once a day at least $1 \mathrm{~h}$ prior to replacement of water. The physico-chemical characteristics of water used in the experiment were determined in accordance with the standard methods (APHA, 2012) and the mean values recorded were: $\mathrm{pH} 7.2 \pm 0.1$, temperature $25 \pm 2^{\circ} \mathrm{C}$, dissolved oxygen $8.0 \pm 0.3 \mathrm{mg} \mathrm{l}^{-1}$, total alkalinity $40 \pm 10 \mathrm{mg} \mathrm{l}^{-1}$ and total hardness $90 \pm 0.5 \mathrm{mg} \mathrm{l}^{-1}$.

\section{Chemicals}

Chlorpyrifos (20\% EC), commercial grade was purchased from Shivalik Insecticide Pvt. Ltd., India. Stock solution was prepared by dissolving the appropriate amount of chlorpyrifos in distilled water which was further used for preparing the working concentrations for acute toxicity tests. Other chemicals of analytical grade $(\mathrm{CDH}$, New Delhi) were procured from local scientific suppliers, Chandigarh, India.

\section{Experimental design}

Static toxicity bioassay was performed following APHA (2012). The short term range finding tests were carried by exposing the fish to wide range of the pesticide concentrations. After performing exploratory experiments, the lowest $\left(6 \mu \mathrm{g} \mathrm{l}^{-1}\right)$ and highest $\left(9 \mu \mathrm{g} \mathrm{l}^{-1}\right)$ concentration of chlorpyrifos (CPF) were selected and three different concentrations of chlorpyrifos viz., 6, 7, $8,9 \mu \mathrm{g} \mathrm{l}^{-1}$ were prepared for the determination of $\mathrm{LC}_{50}$. Ten fish were exposed to each concentration of pesticide in dechlorinated tap water. Appropriate control was also maintained in chlorpyrifos free water. On the basis of percent mortality at each concentration, $96 \mathrm{~h} \mathrm{LC}_{50}$ of CPF was calculated by Probit analysis (Finney, 1980).

For chronic toxicity studies, fish (in three different groups, 20 fish in each group) were exposed to $1 / 3^{\text {rd }}$ of $\mathrm{LC}_{50}\left(2.41 \mu \mathrm{g} \mathrm{l}^{-1}\right)\left(\right.$ Group I) and $1 / 5^{\text {th }}$ of $\mathrm{LC}_{50}\left(1.44 \mu \mathrm{g} \mathrm{l}^{-1}\right)$ (Group II) of $96 \mathrm{~h} \mathrm{LC}_{50}$ of CPF for 15, 30 and 60 days along with control (Group III). Experiments were conducted in duplicates. During the experiment, water was changed daily to avoid the accumulation of faecal matter and to maintain the toxicant concentration. Biochemical analysis of liver of fish exposed to the toxicant and of control was made on $15^{\text {th }}, 30^{\text {th }}$ and $60^{\text {th }}$ day. For this, at the end of each exposure, 6 fish were sacrificed for further analyses.

\section{Biochemical analysis}

The treated and normal fish were euthanised following the guidelines of Institutional Animal Ethical Committee, Panjab University, Chandigarh (Ref no. IAEC/526). and liver tissues were removed for the preparation of homogenate. Tissue was washed in ice cold $0.9 \%$ saline until bleaching of haemoglobin and then chopped to prepare $10 \%$ homogenate in ice-cold $0.1 \mathrm{M}$ Tris $\mathrm{HCl}$ buffer (pH 7.1) with the help of Porter-Elvejhem homogeniser at $4{ }^{\circ} \mathrm{C}$ with motor driven teflon pestle. The homogenate was centrifuged in a refrigerated centrifuge at $12000 \mathrm{rpm}$ for $15 \mathrm{~min}$ and supernatant was used for the estimation of transaminases and phosphatases. ALT and AST activities were estimated as per manufacturer's instructions (Reitman and Frankel, 1957) using colorimetric DNPH (2,4-Dinitrophenylhydrazine) method. Quantitative estimation of ACP and ALP was done as per Bergmeyer (1965). Test kits from Reckon and Erba, Mumbai were used for determination. All the measurements were made in duplicate. Protein was estimated by Lowry et al. (1951) using Bovine Serum Albumin as standard.

\section{Transmission electron microscopy}

For transmission electron microscopy, the liver tissue (1 mm) was washed in $0.1 \mathrm{M}$ phosphate buffer $(\mathrm{pH} 7.2)$ fixed in $2.5 \%$ gluteraldehyde and $2 \%$ paraformaldehyde in $0.1 \mathrm{M}$ phosphate buffer $\left(\mathrm{pH} 7.2,4^{\circ} \mathrm{C}, 2 \mathrm{~h}\right)$ for 10-12 $\mathrm{h}$ and again washed in $0.1 \mathrm{M}$ phosphate buffer ( 3 times), post-fixed in 1\% osmium tetroxide in cacodylate buffer for $1 \mathrm{~h}$ at $4^{\circ} \mathrm{C}$, rinsed with $0.1 \mathrm{M}$ phosphate buffer to remove unutilised osmium tetroxide, dehydrated in increasing acetone concentration solutions and embedded in spur-low viscosity Epon. Sections were cut in an ultramicrotome (Reichert-Jung), stained with $1 \%$ toluidine blue and selected sections were loaded on copper grids for subsequent contrast enhancement with uranyl acetate and lead citrate (Reynolds, 1963). The samples were observed under transmission electron microscope (Leo-Morgagni 268d TEM, Fei company, Netherlands) at All India Institute of Medical Sciences (AIIMS) New Delhi, India.

\section{Statistical analysis}

Statistical analysis of data was carried out using one-way ANOVA with Tukey's test.

\section{Results}

\section{Acute toxicity test}

Acute static bioassay was conducted to determine $\mathrm{LC}_{50}$ of chlorpyrifos to $C$. idella and to select sublethal concentration for chronic toxicity studies. Fish were exposed to different concentrations (6-9 $\mu \mathrm{g} \mathrm{1}^{-1}$ ) of chlorpyrifos with 10 fish in each group for $96 \mathrm{~h}$. Percentage 
mortality after $96 \mathrm{~h}$ exposure to the pesticide at different concentrations were converted to probit scale (Finney, 1980). The $96 \mathrm{~h} \mathrm{LC}_{50}$ was calculated using SPSS 18.0 and was found to be $7.24 \mu \mathrm{g} \mathrm{l}^{-1}$ (Table 1), with regression equation $\mathrm{Y}=0.925 \mathrm{X}+4.1857$ and $\mathrm{r}=0.98$ (Fig. 1).

Enzyme analysis

In the present study, the activity of AST in liver decreased $(0.85$ and $2.6 \%)$ significantly $(p<0.01)$ after 15 days of exposure at lower and higher concentration of
$26.87 \%$ ) concentrations of CPF after 15, 30 and 60 days exposure, respectively (Fig. 4).

The activity of ACP showed significant reduction $(\mathrm{p}<0.05)$ (37.8 and 43.59\%) at 1.44 and $2.41 \mu \mathrm{g} \mathrm{l}^{-1}$ of CPF, respectively after 15 days exposure. Further, on $30^{\text {th }}$ day of exposure, ACP activity showed significant $(\mathrm{p}<0.05)$ decrease (42.8 and $47.2 \%)$ at lower and higher concentration of CPF respectively. On $60^{\text {th }}$ day of exposure, further significant $(\mathrm{p}<0.05)$ reduction in ACP activity $(47.3$ and $54.7 \%)$ at lower

Table 1. Mortality rate of C. idella after $96 \mathrm{~h}$ exposure at different chlorpyrifos concentrations and empirical probit values

\begin{tabular}{lllllll}
\hline Group & Conc. $\left(\mu \mathrm{g} \mathrm{l}^{-1}\right)$ & Log conc. & No. of fish & Dead fish & \% mortality & Probit kill \\
\hline 1 & 6 & 0.77 & 10 & 0 & 10 & 3.72 \\
2 & 7 & 0.84 & 10 & 4 & 40 & 4.75 \\
3 & 8 & 0.90 & 10 & 7 & 70 & 5.52 \\
4 & 9 & 0.95 & 10 & 9 & 90 & 6.28 \\
\hline
\end{tabular}

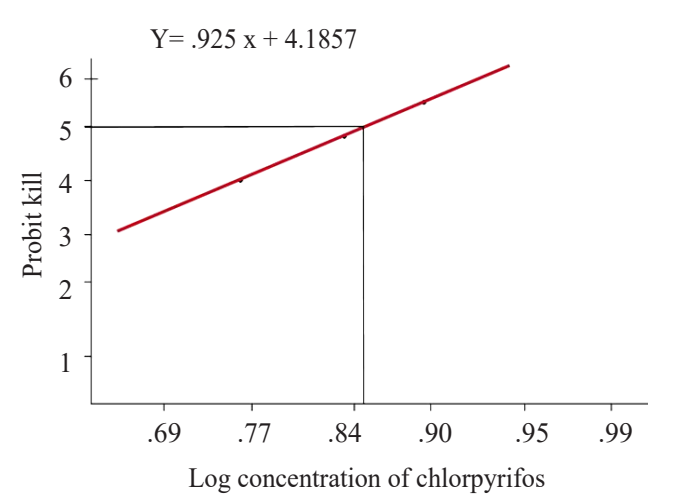

Fig. 1. Regression line between probit kill of C. idella and log concentration of chlorpyrifos

CPF, respectively. Similar significant $(\mathrm{p}<0.05)$ decline in AST activity as compared to control (1.32 and 2.8\%) at lower and higher concentration of toxicant was noticed after 30 days exposure respectively. Further, on exposure of the fish for 60 days, significant $(\mathrm{p}<0.05)$ decrease by 1.03 folds $(2.16 \%)$ in AST activity was observed at lower concentration of the toxicant, whereas at higher concentration, the change (3.7\%) was found to be insignificant (Fig. 2).

The activity of ALT showed significant $(\mathrm{p}<0.05)$ elevation (194 and 255\%) at 1.44 and $2.41 \mu \mathrm{g} \mathrm{l}^{-1}$ of chlorpyrifos, respectively after 15 days exposure. On $30^{\text {th }}$ day, similar marked $(\mathrm{p}<0.05)$ elevation in ALT activity (188 and 209\%) was found at lower and higher concentration of toxicant respectively. Further, after 60 days exposure, significant $(p<0.05)$ elevation in activity of ALT than control (180 and 201\%) at lower and higher concentration of chlorpyrifos, respectively was observed (Fig. 3).

ALP activity showed significant reduction $(\mathrm{p}<0.05)$ at lower (1.59, 4.73 and 17.08\%) and higher (2.52, 13.37 and

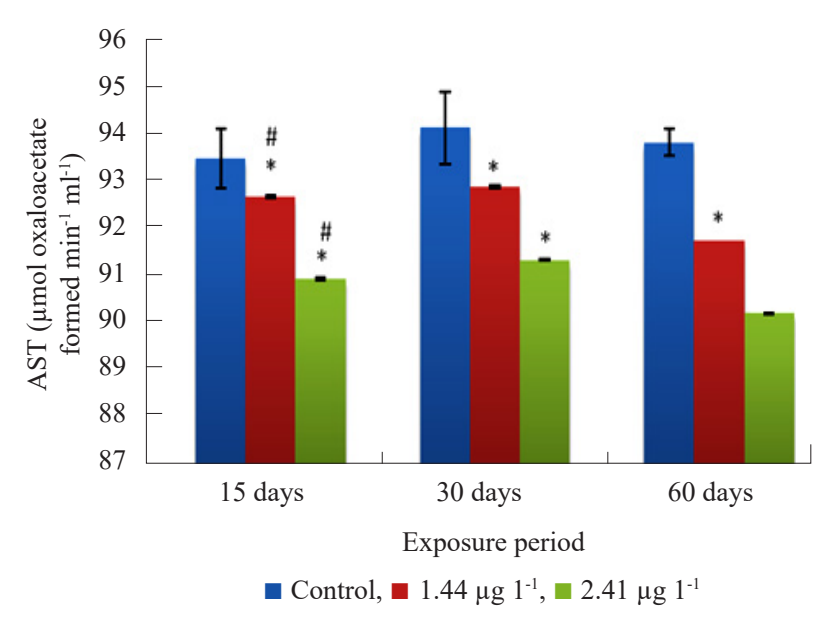

Fig. 2. Variation in the activity of AST in liver of C. idella on exposure to chlorpyrifos

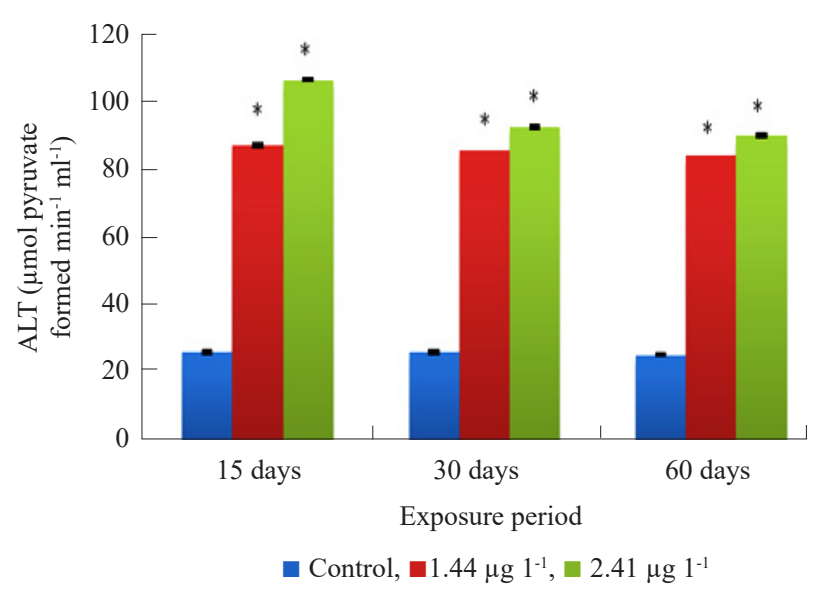

Fig. 3. Variation in the activity of ALT in liver of C. idella on exposure to chlorpyrifos 


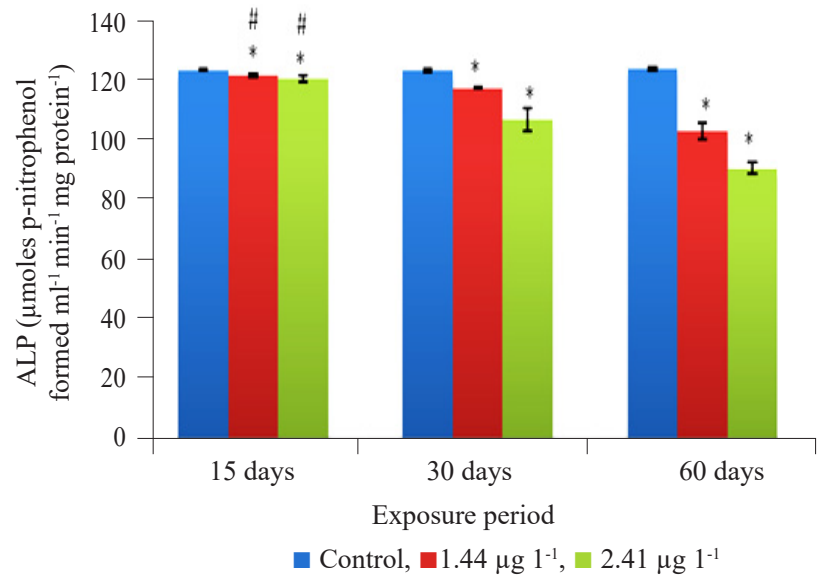

Fig. 4. Variation in the activity of ALP in liver of C. idella on exposure to chlorpyrifos. Data presented as Mean \pm S.D., $\mathrm{n}=6$; " $\mathrm{p}<0.05$; Significant difference; control vs. 1.44 and $2.41 \mu \mathrm{g}^{-1} \mathrm{CPF}$ treated group; $\# \mathrm{p}<0.01$; Significant difference; control vs. 1.44 and $2.41 \mu \mathrm{g} \mathrm{l}^{-1} \mathrm{CPF}$ treated group

and higher concentrations of chlorpyrifos, respectively was observed (Fig. 5).

\section{Liver ultrastructure}

The ultrastructure of control fish liver showed ovoid nucleus having scattered heterochromatin and distinct nucleolus. Rough endoplasmic reticulum (RER) with extensive stacks of cisternae was interspersed with some mitochondria, formed continuous sheath around the nucleus (Fig $6 \mathrm{a}, \mathrm{b}$ ). The RER were found to be regularly bordered by spherical peroxisomes and were regularly separated from glycogen fields. Mitochondria often observed were the most prominent organelle of hepatocytes and were characterised by double membranes with closely packed prominent cristae (Fig 6 a, b).

Marked disruption in the hepatic ultrastructure was observed in $C$. idella on exposure to chlorpyrifos for 15 days.

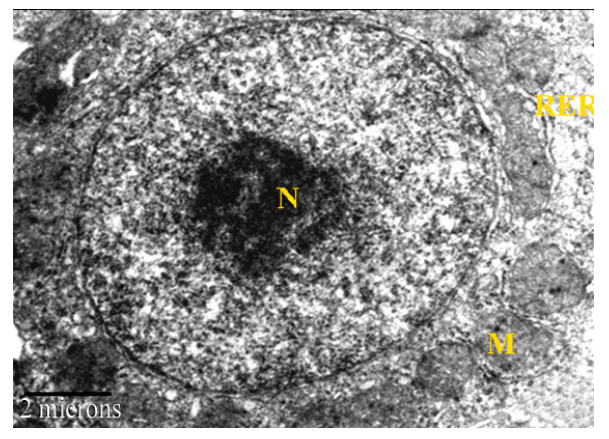

(a)

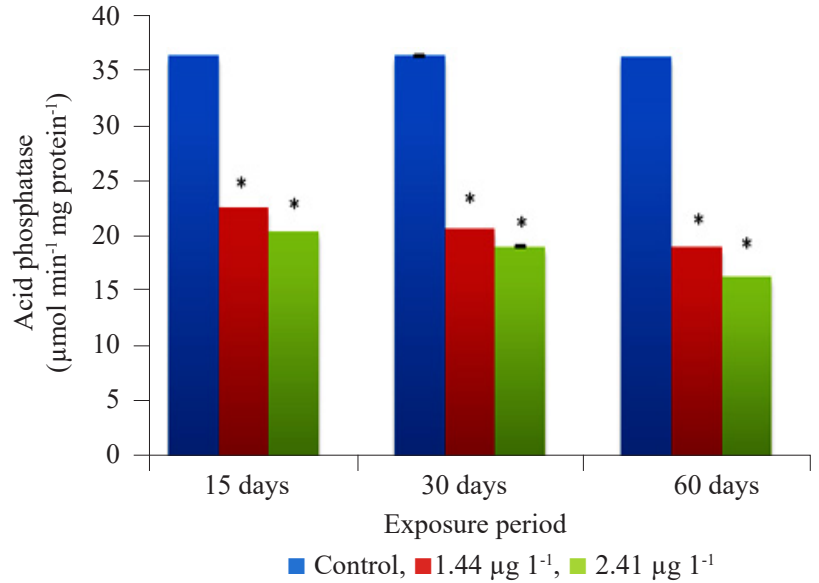

Fig. 5. Variation in the activity of ACP in liver of C. idella on exposure to chlorpyrifos. Data presented as Mean \pm S.D., $\mathrm{n}=6 ;{ }^{*} \mathrm{p}<0.05$; Significant difference; control $v s .1 .44$ and $2.41 \mu \mathrm{g} \mathrm{l}^{-1}$ CPF treated group; $\# \mathrm{p}<0.01$; Significant difference; control vs. 1.44 and $2.41 \mu \mathrm{g} \mathrm{l}^{-1} \mathrm{CPF}$ treated group

In some cells, nuclei were found to be deformed with condensed chromatin and a cluster of clumped mitochondria was seen surrounding nucleus at both the concentrations of the toxicant. The cytoplasm showed elongated mitochondria with irregular shape and size and their vacuolisation with distorted cristae, dilated and fragmented smooth endoplasmic reticulum (SER), scattered glycogen granules and lipid droplets (Fig 7 a-d).

On exposure of the fish to $\mathrm{CPF}$ for 30 days at 2.41 and $1.44 \mu \mathrm{g} \mathrm{l}^{-1}$ sublethal concentrations, more pronounced alterations in the cellular components were observed (Fig 8 a-d). The hepatocyte nucleus lost its shape and became elongated. The double layered nuclear membrane got dilated and separated. Cytoplasm was found to be occupied with large number of glycogen granules. Numerous vacuoles, swollen mitochondria with loose network of few dilated cristae, dilated cisternae of endoplasmic reticulum were also seen. Numerous dilated RER were found to be coiled forming circular structures. Granular ribosomes got detached and scattered in the cytoplasm.

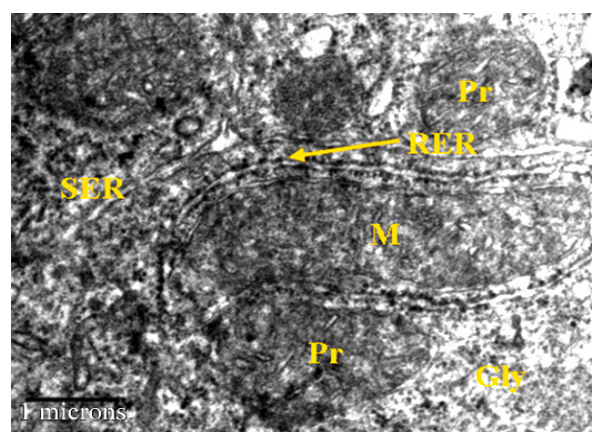

(b)

Fig. 6. Transmission electron micrographs of hepatocytes of Ctenopharyngodon idella of control group (a, b) showing ovoid nucleus $(\mathrm{N})$, scattered heterochromatin, distinct nucleolus $(\mathrm{Nu})$, rough endoplasmic reticulum (RER) with extensive stacks of cisternae, smooth endoplasmic reticulum (SER), mitochondria (M), spherical peroxisomes (Pr) and glycogen fields (Gly) 


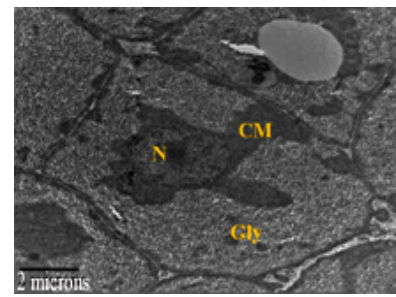

(a)

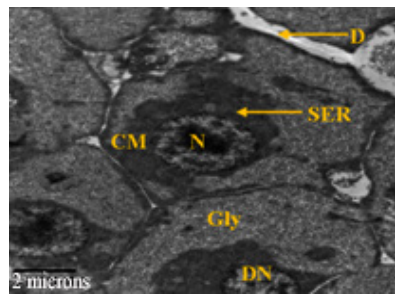

(b)

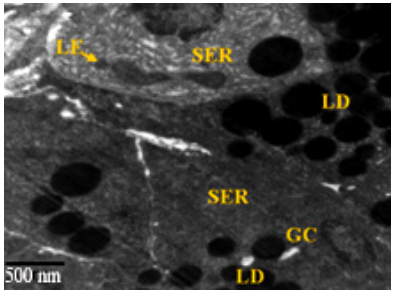

(c)

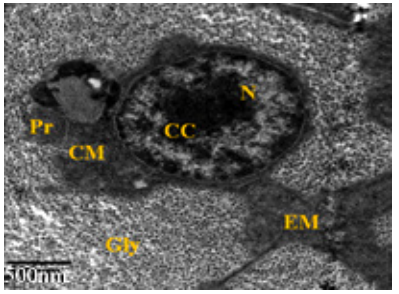

(d)

Fig 7. Transmission electron micrographs of hepatocytes of Ctenopharyngodon idella exposed to $1.44 \mu \mathrm{g} 1^{-1}(\mathrm{a}, \mathrm{b})$ and $2.41 \mu \mathrm{g} \mathrm{1^{-1 }}$ (c, d) of chlorpyrifos for 15 days showing deformed nuclei (DN) with condensed chromatin (CC), clumped mitochondria (CM), elongated mitochondria (EM), dilated and fragmented SER, scattered glycogen granules (a,c,d) and lipid droplets (LD)

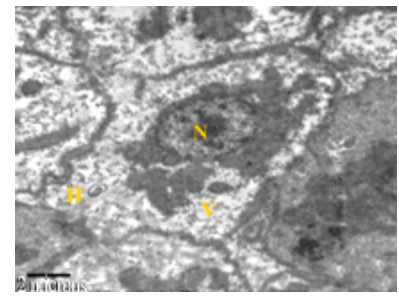

(a)

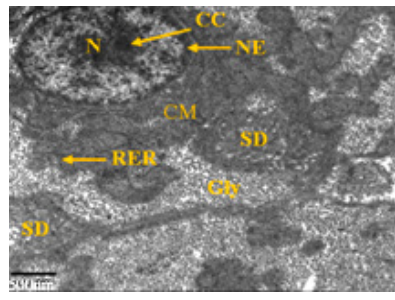

(b)

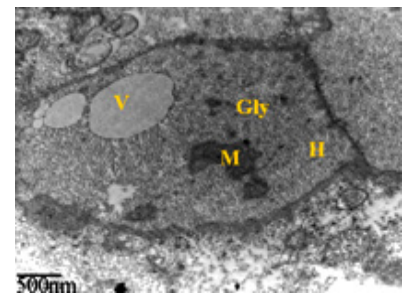

(c)

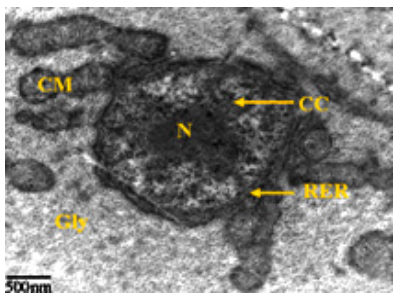

(d)

Fig. 8. Transmission electron micrographs of hepatocytes of Ctenopharyngodon idella exposed to $1.44 \mu \mathrm{g} \mathrm{1^{-1 }}(\mathrm{a}, \mathrm{b})$ and $2.41 \mu \mathrm{g} \mathrm{1^{-1 }}$ (c, d) chlorpyrifos for 30 days showing dilated nuclear membrane (NE) (b), condensed chromatin (CC), glycogen granules (Gly), vacuolisation (V) (a, c), swollen mitochondria with loose network of dilated cristae (b, d) and dilated cisternae of RER (c, d)

On exposure of the fish to chlorpyrifos at lower concentration for 60 days, many degenerative changes were observed. There was formation of crescent shaped nucleus along with condensed chromatin, severe breakdown and fragmentation of endoplasmic reticulum and clumped mitochondria was also seen. There was total destruction of the cell with severe vacuolisation and scattered glycogen granules (Fig $9 \mathrm{a}, \mathrm{b})$. At higher concentration $\left(2.41 \mu \mathrm{g} \mathrm{l}^{-1}\right)$ of chlorpyrifos, severe mitochondrial malformation along with condensation of its matrix, disorganisation of RER and loss of ER in some cells and accumulation of lipid droplets were noticed (Fig $9 \mathrm{c}, \mathrm{d}$ ).

\section{Discussion}

Based on $96 \mathrm{~h} \mathrm{LC}_{50}$, it was observed that $C$. idella is more sensitive to chlorpyrifos than Oncorhynchus mykiss

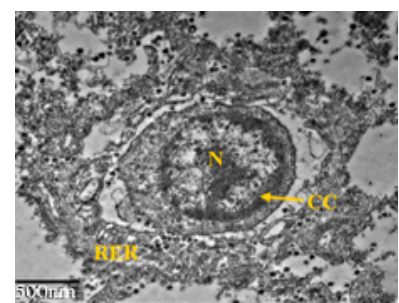

(a)

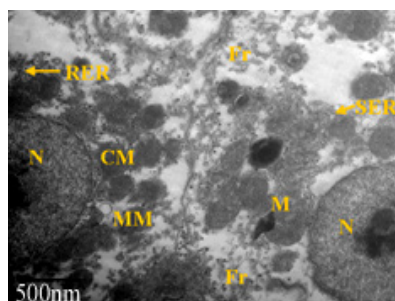

(b)
(24 $\mu \mathrm{g} \mathrm{l}^{-1}$ ) (Mayer and Ellersieck, 1986); Nile tilapia (1.57 $\mathrm{mg} \mathrm{l}^{-1}$ ) (Gul, 2005); Oreochromis mossambicus (25.7 $\mathrm{g} \mathrm{l}^{-1}$ ) (Rao et al., 2003) and Cyprinus carpio $\left(580 \mu \mathrm{g} \mathrm{l}^{-1}\right)$ (Xing et al., 2011). Jindal and Kaur (2015) rated chlorpyrifos as highly toxic to fish. The difference in $\mathrm{LC}_{50}$ value could be attributed to physico-chemical characteristics of water (Yorulmazlar and Gul, 2003) and variation in susceptibility and tolerance related to differences in rates of accumulation, biotransformation and excretion of toxicant (Pandey et al., 2009).

Enzyme analysis and ultrastructural changes in liver have proven to be suitable and sensitive indicators of toxicant-induced injury and have been used as biomarkers of chemicals in environmental risk assessments (Boeger et al., 2003). ALT and AST are more sensitive measures of hepatotoxicity and can be assessed within a shorter period

Fig. 9. Transmission electron micrographs of hepatocytes of Ctenopharyngodon idella exposed to $1.44 \mu \mathrm{g} \mathrm{l^{-1 }}(\mathrm{a}, \mathrm{b})$ and $2.41 \mu \mathrm{g} \mathrm{1^{-1 }}$ (c, d) chlorpyrifos for 60 days showing crescent shaped and ruptured (RN) nucleus (a), condensed chromatin (b), severe breakdown and fragmentation of endoplasmic reticulum (a-d), clumped mitochondria (b, c), severe vacuolisation (c), scattered glycogen granules $(a, b)$, severe mitochondrial malformation (MM), disorganised and fragmented (Fr) RER and SER (b, d) and karyolysis $(\mathrm{Kr})$.

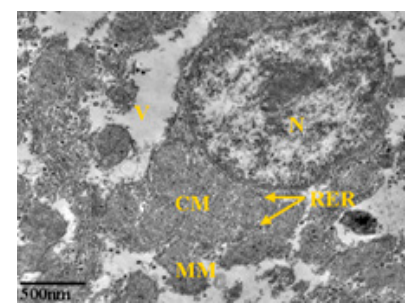

(c)

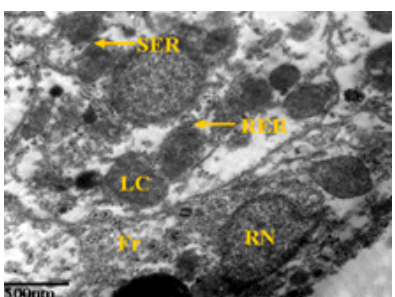

(d) 
of time (Balint et al., 1997). Initial marked elevation in ALT activity as well as initial reduction in ALP and ACP activity in liver as observed during the present study indicate damage and alteration in function of the organ.

During the present investigation, fluctuation in AST and ALT activity in liver of $C$. idella was observed. This is in agreement with the findings in Heteropneustes fossilis exposed to malathion (Goel et al., 1992); C. idella exposed to fenvalerate (Shakoori et al., 1996); Catla catla exposed to fenvalerate (Susan et al., 1999) and deltamethrin (Vani et al., 2011). The observed fluctuations in AST and ALT activity in the above studies were attributed to pesticide toxicity, disturbance in TCA cycle and leakage of enzymes from the organ. They also stated that oxaloacetate and glutamate are not available to Krebs cycle through this route transamination. Correlation was observed between aminotransferases activity and mitochondrial integrity, as any modification in mitochondrial structure is bound to alter associated enzyme system, evidenced by transmission electron microscopy of the liver (Bonitenko, 1974). Fluctuation in the activity of transaminases might be due to the organ dysfunction under the effect of oxidative stress by enhanced generation of reactive oxygen species (Nayak et al., 2004). Amin and Hashem (2012) while working on the effect of deltamethrin on Clarias gariepinus inferred that ALT and AST are the most commonly used biochemical markers of cellular necrosis. Present findings are in concurrence with the findings of above workers.

Acid and alkaline phosphatases are lysosomal hydrolytic enzymes present in all the tissues. They are concerned with the process of transphosphorylation, that hydrolyses the phosphoesters in acidic medium and are also associated with the transportation of metabolites, metabolism of phospholipids, phosphoproteins, nucleotides and carbohydrate and synthesis of proteins (Srivastava and Pandey, 1982). During the present study, the chlorpyrifos exposed fish showed decreased levels of phosphatase (ACP and ALP) activity in liver. This could be attributed to altered structural integrity of cell organelles as evidenced by TEM studies and decreased rate of transphosphorylation or coupling of oxidative phosphorylation (Saha and Kaviraj, 2009; Magar and Shaikh, 2013). Rao (2006a, b) reported ACP and ALP activity inhibition in liver and related this to increased lysosomal mobilisation and cell necrosis due to pesticide toxicity. Begum (2004) explained that inhibition of phosphatase activity is related to breakdown of glycogen to meet the energy demand under toxicant stress. Gabriel and George (2005) also stated that under various adaptive conditions, transamination is the main pathway for synthesis and deamination of amino acids, activating carbohydrates and protein metabolism during energy demands of the fish.
Alterations in liver are suitable indicators of exposure to environmental stressors. The loss of regular cytoplasmic compartmentation as noticed during the present study is a typical ultrastructural response of fish hepatocytes which depicts disturbance of hepatocellular homeostasis (Gernhofer et al., 2001). Further, changes observed in the hepatocyte nuclei and condensation of heterochromatin could be the result of accumulation of chlorpyrifos in the liver. Toxicant induced ultrastructural alterations like condensation of chromatin and mitochondrial vacuolisation reported in the liver of snakehead Channa punctatus (Khangarot, 1992) were similar to those found in the present study.

Degeneration of mitochondria observed in the hepatocytes of $C$. idella may be attributed to the impairment of oxidative potential of hepatocytes in CPF exposed fish. Marked ultrastructural alterations in mitochondria including their swelling with loss of functional cristae have also been reported in freshwater fish exposed to methyl parathion (Tripathi and Shukla, 1990). Marked swelling of mitochondria could be attributed to the enhanced energy requirements of the cells to overcome stress induced by the toxic effect of chlorpyrifos. Similarly, swelling of mitochondria and ER cisternae in the liver of treated Dicentrarchus labrax have also been observed by Giari et al. (2008). In the present study, long period of exposure of chlorpyrifos resulted in scattered glycogen content and caused disintegration of cytoplasmic organelles. This indicated that chlorpyrifos can disturb the metabolic pathways of hepatocytes (Cheville, 1994). Lee et al. (2014) reported black granules in lysosomes, indistinct nuclear membrane and non-spherical nucleus in Cyprinus carpio induced by zinc. Chlorpyrifos also induced similar alterations in hepatocytes of $C$. idella.

To conclude, biochemical and electron microscopic studies revealed that exposure period and concentration of chlorpyrifos affected response in hepatocytes of the exposed fish to chlorpyrifos. Ultrastructural changes could be correlated to corresponding alterations observed in activity of marker enzymes. At both the toxicant concentrations, activity of alanine aminotransferase as marker of cytosolic glycolysis and protein metabolism got altered indicating disturbances in the cellular metabolism. Thus, the observed alterations in the marker enzyme levels can be used as sensitive biomarkers for chlorpyrifos contamination. It could also be inferred that chlorpyrifos is a potent metabolic obstructer to $C$. idella even at sublethal concentrations.

\section{Acknowledgements}

The authors are thankful to the Chairperson, Department of Zoology, Panjab University, Chandigarh for providing necessary research facility, AIIMS, New Delhi for TEM analyses and to the University Grants Commission, New Delhi, India for providing financial assistance to carry out this work. 


\section{References}

Amin, K. A. and Hashem, K. S. 2012. Deltamethrin-induced oxidative stress and biochemical changes in tissues and blood of catfish (Clarias gariepinus): antioxidant defense and role of alpha-tocopherl. BMC Vet. Res., 8(1): 45 pp.

APHA 2012. Standard methods for the examination of water and waste water. American Public Health Association, $22^{\text {nd }}$ edn. American Public Health Association, Washington DC, USA.

Balint, T., Ferenczy, J., Katai, F., Kiss, I., Kraczer, L., Kufcsak, O., Lang, G., Polyhos, C., Szabo, I., Szegletes, T. and Nemcsok, J. 1997. Similarities and differences between the massive eel (Anguilla anguilla L.) devastations that occurred in Lake Balaton in 1991 and 1995. Ecotoxicol. Environ. Saf., 37: $17-23$.

Begum, G. 2004. Carbofuran insecticide induced biochemical alterations in liver and muscle tissues of fish Clarias batrachus (Linn) and recovery response. Aquat. Toxicol., 66(1): 83-92.

Bergmeyer, H. U. 1965. Methods for determination of enzyme activity. In: Bergmeyer, H. U. (Ed.), Methods in enzymatic analysis. Academic Press, New York, 1047 pp.

Bernet, D, Schmidt, H., Wahli, T. and Burkhardt-Holm, P. 2001. Effluent from a sewage treatment works causes changes in serum chemistry of brown trout (Salmo trutta L.). Ecotoxicol. Environ. Saf., 48: 140-147.

Boeger, W., Ostrasky, A., Guimaraes, A. T. B. and Romao, S. 2003. Histopathology as an approach to evaluate the effect of the oil spill on fishes of the rivers Saldanha Barigui and Igvacu (Brazil). Int. Spill Conf., 2(3): 100-110.

Bonitenko, Y. U. 1974. Isoenzymes of aspartate aminotransferase in acute dichloro ethane poisoning. Gig. Tr. Prof. Zebo., 7: 46-47.

Bowser, P. R., Martinea, D., Sloan, R., Brown, M. and Carisone, C. 1990. Prevalence of liver lesions in brown bullheads from polluted site and a non-polluted reference site on the Hudson River, New York. J. Aquat. Anim. Health, 2: 177-181.

Braunbeck, T., Burkhardt-Holm, P. and Storch, V. 1990. Liver pathology in cells (Anguilla anguilla, L.) from the Rhine River exposed to the chemical spill at Barle in November, 1986. Limmol Aktuell, 1: 371-392.

Brusle, J. and Gonzalez, G. 1995. The structure and function of fish liver. In: Fish morphology. horizon of new research. In: Dutta Munshi, J. S. and Dutta, H. M. (Eds.), Oxford and IBH Publishing Co. Pvt. Ltd., New Delhi, Bombay, Calcutta, p. 77-98.

Carrola, J., Fontainhas-Fernandes, A., Matos, P. and Rocha, E. 2009. Liver histopathology in brown trout (Salmo trutta f. fario) from the Tinhela River, subjected to mine drainage from the abandoned Jales Mine (Portugal). Bull. Environ. Contam. Ecotoxicol., 83: 35-41.

Cheville, N. F. 1994. Ultrastructural pathology: An introduction to interpretation, $\mathrm{I}^{\text {st }}$ edn. Ames, Iowa State University Press, Iowa, $946 \mathrm{pp}$.
Fernandes, C., Fontainhas-Fernandes, A., Rocha, E. and Salgado, M. A. 2008. Monitoring pollution in Esmoriz-Paramos Lagoon, Portugal: Liver histological and biochemical effects in Liza saliens. Environ. Monit. Assess., 145: 315-322.

Finney, D. J. 1980. Probit analysis, $3^{\text {rd }}$ edn. Cambridge University Press, London and New York.

Gabriel, U. U. and George, A. D. 1. 2005. Plasma enzymes in C. gariepinus exposed to chronic levels of roundup (glyphosate). Environ. Ecol., 23: 271-276.

Gernhofer, M., Pawet, M., Schramm, M., Muller, E. and Triebskorn, R. 2001. Ultrastructural biomarkers as tools to characterise the health status of fish in contaminated streams. J. Aquat. Ecosyst. Stress Recovery, 8: 241-260.

Giari, L., Simoni, E., Manera, M. and Dezfuli, B. S. 2008 Histocytological responses of Dicentrarchus labrax (L.) following mercury exposure. Ecotoxicol. Environ. Saf., 700(3): 400-410.

Goel, K. A., Tyagi, S. K. and Awasthi, A. K. 1992. Effect of malathion on some haematological values in Heteropneustes fossils. Comp. Physiol. Ecol., 7: 259-261.

Gul, A. 2005. Investigation of acute toxicity of chlorpyrifosmethyl on Nile tilapia (Oreochromis niloticus L.) larvae. Chemosphere, 59: 163-166.

Jacobson-Kram, D. and Keller, K. A. 2006. Toxicology testing handbook, $2^{\text {nd }}$ edn., Marcel Dekker, New York, 499 pp.

Jindal, R. and Kaur, M. 2015. Ultrastructural alterations in scales of Ctenopharyngodon idellus (Cuvier and Valenciennes) induced by chlorpyrifos: a promising tool as bioindicator of pesticide pollution. Int. J. Fish. Aquat. Stud., 2(3): 58-62.

Khangarot, B. S. 1992. Copper-induced hepatic ultrastructural alterations in the snakehead fish, Channa punctatus. Ecotoxicol. Environ. Saf., 125: 101-181.

Lee, J. W., Kim, J. E., Shin, Y. J., Ryu, J. S., Eoma, I. C., Lee, J. S., Kim, Y., Kim, P. J., Choi, K. H. and Lee, B. C. 2014. Serum and ultrastructure responses of common carp (Cyprinus carpio L.) during long-term exposure to zinc oxide nanoparticles. Ecotoxicol. Environ. Saf., 104: 9-17.

Lowry, O. H., Rosebrough, N. J., Farr, A. L. and Randall, R. J. 1951. Protein measurement with folin phenol reagent. J. Biol. Chem., 193: 265-275.

Magar, R. S. and Shaikh, A. 2013. Effect of malathion toxicity on detoxifying organ of freshwater fish, Channa punctatus. Int. J. Pharm.Chem. Biol. Sci., 3(3): 723-728.

Martin, J. H. and Knaeur, G. A. 1973. The elemental composition of phytoplankton. Geochem. Cosmochem. Acta, 37: 1639.

Mayer, F. L. Jr. and Ellersieck, M. R. 1986. Manual of acute toxicity. Interpretation and database of 410 chemicals 66 species of freshwater animals. Resource Publication160 U.S. Fish and Wild Life Sciences, Washngton D.C.

Nayak, A. K., Das, B. K., Kohli, M. P. S and Mukherjee, S. C. 2004. The immunosuppressive effect of $\alpha$-permethrin on 
Indian major carp, rohu (Labeo rohita Ham.). Fish Shellfish Immunol., 16: 41-50.

Oluah, N. S., Ezigbo, J. C and Anya, N. C. 2005. Effect of exposure to sublethal concentrations of Gammalin 20 and Actellic 25 $\mathrm{EC}$ on the liver and serum lactate dehydrogenase activity in the fish Clarias albopunctatus. Anim. Res. Int., 2(1): 231-234.

Pandey, R. K., Singh, R. N., Singh, S., Singh, N. N. and Das, V. K. 2009. Acute toxicity bioassay of dimethoate on freshwater airbreathing catfish, Heteropneustes fossilis (Bloch). J. Environ. Biol., 30(3): 437-440.

Rao, J. V. 2006a. Toxic effects of novel organophosphorus insecticide (RPR-V) on certain biochemical parameters of euryhaline fish, Oreochromis mossambicus. Pest. Biochem. Physiol., 86: 78-84.

Rao, J. V. 2006b. Biochemical alterations in euryhaline fish, Oreochromis mossambicus exposed to sub-lethal concentrations of an organophosphorus insecticide, monocrotophos. Chemosphere, 65: 1814-1820.

Rao, J. V., Rani, C. H. S., Kavitha, P., Rao, R. N. and Madhavendra, S. S. 2003. Toxicity of chlorpyrifos to the fish, Oreochromis mossambicus. Bull. Environ. Contam. Toxicol., 70: 985-992.

Reitman, S. and Frankel, S. 1957. A colorimetric method for the determination of serum glutamic oxaloacetate and glutamic pyruvic transaminases. Am. J. Clin. Pathol., 28(1): 56-63.

Reynolds, E. S. 1963. The use of lead citrate at high $\mathrm{pH}$ as an electron opaque stain in electron microscopy. J. Cell. Biol., 17: $208-212$.

Saha, S. and Kaviraj, A. 2009. Effects of cypermethrin on some biochemical parameters and its amelioration through dietary supplementation of ascorbic acid in freshwater catfish Heteropneustes fossilis. Chemosphere, 74: 1254-1259.
Shakoori, A. K., Mughal, A. L. and lqbal, M. J. 1996. Effects of sublethal doses of fenvalerate (a synthetic pyrethroid) administered continuously for four weeks on the blood, liver and muscles of a freshwater fish, Ctenopharyngodon idella. Bull. Environ. Contam. Toxicol., 57: 487-494.

Srivastava, D. K. and Pandey, K. C. 1982. Effect of copper on tissue acid and alkaline phosphatases in the green snakehead, Ophiocephalus punctatus (Bloch). Toxicol. Lett., 11: 237-241.

Susan, T. A., Sobha, K., Veeraiah, K. and Tilak, K. S. 1999. Studies on biochemical changes in the tissues of Labeo rohita and Cirrhinus mrigala exposed to fenvalerate technical grade. J. Toxicol. Environ. Health Sci., 2(5): 53-62.

Tripathi, G. and Shukla, S. P. 1990. Enzymatic and ultrastructural studies in a freshwater catfish: Impact of methyl parathion. Biomed. Environ. Sci., 3: 166-182.

Vani, T., Saharan, N., Mukherjee, S. C., Ranjan, R., Kumar, R. and Brahmchari, R. K. 2011. Deltamethrin induced alterations of hematological and biochemical parameters in fingerlings of Catla catla (Ham.) and their amelioration by dietary supplement of vitamin C. Pest. Biochem. Physiol., 101: 16-20.

Velisek, J., Jurcikova, J., Dobsikova, R., Svobodova, Z., Piackova, V., Machova, J. and Novotny, L. 2007. Effects of deltamethrin on rainbow trout (Oncorhynchus mykiss). Environ. Toxicol. Pharmacol., 23: 297-301.

Xing, H., Wang, X., Sun, G., Gao, X., Xu, S. and Wang, X 2011. Effects of atrazine and chlorpyrifos on activity and transcription of glutathione S-transferase in common carp (Cyprinus carpio L). Environ. Toxicol. Pharmacol., 33: $233-244$.

Yorulmazlar, E. and Gul, E. 2003. Investigation of acute toxicity of cadmium sulfate $\left(\mathrm{CdSO}_{4} \cdot \mathrm{H}_{2} \mathrm{O}\right)$ and behavioral changes of grass carp (Ctenopharyngodon idellus Val., 1844). Chemosphere, 53: 1005-1010. 